\title{
OPTIMASI TEMPERATUR DAN KONSENTRASI NaOH PADA PEMBUATAN KARBOL DARI MINYAK JELANTAH
}

\section{OPTIMIZATION OF TEMPERATURE AND CONCENTRATION OF NAOH IN THE MANUFACTURING OF CARBOL FROM COOKING OIL}

\author{
Sukmawati, Pratiwi Putri Lestari* \\ LLDIKTI Wilayah I Medan \\ *Corresponding author: tiwietri2015@gmail.com
}

\begin{abstract}
ABSTRAK
Penelitian ini bertujuan untuk mengetahui cara pemanfaatan minyak jelantah dengan cara membuatnya menjadi pembersih lantai, agar mengetahui titik optimum dalam pembuatan karbol dari minyak jelantah. Pada proses pembuatan karbol dari minyak jelantah, digunakan metode pemanasan untuk pembuatannya. Adapun tahapan penenlitian ini dimulai dari preparasi bahan pembuatan, penjernihan awal bahan pembuatan, analisa warna, analisa koefisien fenol, analisa $\mathrm{pH}$, dan analisa stabilitas pada air sadah. Berdasarkan hasil analisa yang paling optimum didapat pada karbol minyak jelantah dengan pemasakan di temperatur $90{ }^{\circ} \mathrm{C}$. Pada konsentrasi $\mathrm{NaOH} 10 \%$ nilai yang didapat $\mathrm{pH}=7$, koefisien fenol $=2,22$, warna = coklat, stabilitas emulsi pada air sadah $=$ stabil. Pada konsentrasi $\mathrm{NaOH} 20 \%$ nilai yang didapat $\mathrm{pH}=9$, koefisien fenol $=$ 2,22, warna $=$ coklat, stabilitas emulsi pada air sadah $=$ stabil. Pada konsentrasi $\mathrm{NaOH} 30 \%$ nilai yang didapat $\mathrm{pH}=10$, koefisien fenol $=2,77$, warna $=$ coklat, stabilitas emulsi pada air sadah $=$ stabil. Pada konsentrasi $\mathrm{NaOH} 40 \%$ nilai yang didapat $\mathrm{pH}=11$, koefisien fenol $=2,77$, warna $=$ coklat, stabilitas emulsi pada air sadah = stabil. Hasil yang diperoleh sesuai dengan BSN (SNI-06-1842-1995).
\end{abstract}

Kata kunci: Desinfektan; Karbol; Minyak Jelantah

\begin{abstract}
This study aims to find out how to use used cooking oil by making it a floor cleaner, in order to find out the optimum point in making carbolic acid from used cooking oil. In the process of making carbolic acid from used cooking oil, a heating method is used for its manufacture. The stages of this research are starting from the preparation of the manufacturing materials, the initial purification of the manufacturing materials, color analysis, phenol coefficient analysis, $\mathrm{pH}$ analysis, and stability analysis in hard water. Based on the results of the analysis, the most optimum was obtained from used cooking oil carbolic acid by cooking at a temperature of $90{ }^{\circ} \mathrm{C}$. At $10 \% \mathrm{NaOH}$ concentration the value obtained was $\mathrm{pH}=7$, phenol coefficient $=$ 2.22, color $=$ brown, emulsion stability in hard water $=$ stable. At $20 \% \mathrm{NaOH}$ concentration the value obtained was $p H=9$, phenol coefficient $=2.22$, color $=$ brown, emulsion stability in hard water $=$ stable. At $30 \% \mathrm{NaOH}$ concentration the value obtained was $\mathrm{pH}=10$, phenol coefficient $=2.77$, color $=$ brown, emulsion stability in hard water $=$ stable. At $40 \% \mathrm{NaOH}$ concentration the value obtained was $p H=11$, phenol coefficient $=2.77$, color $=$ brown, emulsion stability in hard water $=$ stable. The results obtained are in accordance with BSN (SNI-06-1842-1995).
\end{abstract}

Keywords: Disinfectan; Carbolic Acid; Cooking Oil. 


\section{PENDAHULUAN}

Minyak jelantah adalah minyak hasil penggorengan yang telah digunakan berulang-ulang kali. Akibatnya, minyak akan menerima banyak panas selama pemakaian sehingga memutus ikatan rangkap dan membuat minyak jelantah memiliki kandungan asam lemak bebas yang tinggi. Minyak jelantah bersifat karsinogenik dan dapat menimbulkan penyakit seperti kanker dan penyempitan pembuluh darah apabila dikonsumsi dalam jumlah yang banyak.

Salah satu cara untuk mengurangi kandungan kontaminan dalam minyak goreng bekas adalah pemurnian melalui proses penyaringan. Proses ini dapat menyerap zat-zat yang tidak diinginkan dalam minyak goreng bekas denganmenggunakan kertas saring. Unsur-unsur kimia dalam minyak goreng (misalnya trigliserida) memiliki diameter kinetik yang terlalu besar dan akan membuat unsur-unsur ini tidak dapat melewati pori-pori kertas saring sehingga secara efektif unsur-unsur kimia ini akan tersaring. Dengan demikian, secara teori maka separasi unsur-unsur kimia dari minyak goreng bekas dapat dilakukan dengan cara penyaringan (Latiful Qolby, 2015).

Dalam penelitian sebelumnya menggunakan konsentrasi $\mathrm{NaOH}$ pada $30 \%$ dan tidak menggunakan pemanasan pada pembuatannya. Namun, pada penelitian selanjutnya dengan mengubah konsentrasi sebelumnya dan menggunakan pemanasan pada pembuatannya.

\section{METODE PENELITIAN}

\subsection{Bahan dan Alat}

Alat yang digunakan antara lain: Mortar, Hot plate stirer, Neraca Analitik, Ayakan. Bahan yang dibutuhkan adalah Minyak Jelantah, Naftalena, Arpus, NaOH, Air, Fenol, Karbon aktif, KOH.

Variabel dan Kondisi Proses

- Variabel tetap proses:

- Minyak Jelantah

- Naftalena

- Arpus

- Variabel Berubah Proses:

- Temperatur : : 70, 80, $90,100{ }^{\circ} \mathrm{C}$

- Konsentrasi $\mathrm{NaOH}: 10,20,30,40 \%$

- Variabel Analisa:

- Warna, pH, Keofesien Fenol, Stabilitas Emulsi pada Air Sadah

\subsection{Prosedur Penjernihan Minyak Jelantah}

10 gram karbon diaktifasi didalam 20 laruan aktivator $\mathrm{KOH}$ dengan konsentrasi $10 \%$, menyaring karbon dengan kertas saring dan mencucinya dengan aquadest hingga $\mathrm{pH} 7$, kemudian mengeringkan arang aktif, lalu menyiapkan minyak jelantah $400 \mathrm{ml}$ di dalam beaker glass, lalu dimasukkan bubuk karbon aktif ke dalam beaker glass dan rendam arang aktif dan minyak selama 24 jam kemudian di saring.

\subsection{Prosedur Pembuatan Karbol}

Menghaluskan arpus $50 \mathrm{~g}$ dengan mortar kemudian diayak, menghaluskan naftalena 2,5 gr dengan mortar, memanaskan $500 \mathrm{ml}$ air hingga suhu $70{ }^{\circ} \mathrm{C}$, Kemudian ditambahkan 50 gr arpus halus perlahanlahan sambil terus mengaduknya, Menambahkan $25 \mathrm{ml}$ larutan $\mathrm{NaOH} 10 \%$ sedikit demi sedikit sampai semua arpus larut. Lartan didiamkan selama 20 menit, melarutkan 2,5 gr naftalena halus ke dalam $20 \mathrm{ml}$ minyak jelantah yang telah disaring, Agar naftalena larut ke dalam minyak jelantah, memanaskan campuran tersebut di atas penangas air, Kemudian menambahkan campuran arpus dan air ke dalam minyak jelantah sambil terus mengaduknya, Memasukkan karbol minyak jelantah kedalam botol plastik, Melakukan analisa warna, analisa $\mathrm{pH}$, analisa koefisien fenol, dan kelarutan dalam air. 


\subsection{Prosedur Analisa Warna}

Mengamati warna yang terdapat pada sampel karbol, Mencatat warna yang terlihat.

\subsection{Prosedur Analisa Stabilitas dalam Air Sadah}

Menyiapkan $100 \mathrm{ml}$ air di dalam beaker glass, Menambahkan $20 \mathrm{ml}$ karbol minyak jelantah, dan mengamati perubahan yang terjadi.

\subsection{Prosedur Analisa Koefisien Fenol}

\section{a. Prosedur Penyiapan Analisa}

Menyiapkan medium Nutrient Agar sebanyak 15 gr, kemudian dilarutkan dengan 1 liter aquadest. Memanaskannya dan mengaduk dengan hot plate stirrer, Setelah larut, memasukkan larutan itu ke dalam tabung reaksi sebanyak $5 \mathrm{ml}$, kemudian media-media tersebut diingkubasi dan didiamkan selama 24 jam, Menyiapkan medium Nutrient Borth sebanyak 5 gr di larutkan dalam 1 liter aquadest kemudian diaduk menggunakan magnetic stirrer dan diinkubasi, Meremajakan bakteri uji dengan menginokulasikannya ke dalam medium NA dan diingkubasi selama 24 jam, Mengambil bakteri yang telah diremajakan sebanyak 1 ose dan menginokulasikannya ke erlenmeyer berisi $30 \mathrm{ml}$ medium NB dan menginkubasi selama 24 jam, Mengambil $5 \mathrm{ml}$ produk karbol lalu menambahkan aquadest hingga $100 \mathrm{ml}$, sehingga didapat produk dengan konsentrasi $5 \%$. Setelah itu membuat seri pengenceran dengan perbandingan berikut :

Tabel 1.Faktor Pengenceran Produk

\begin{tabular}{cccc}
\hline Produk 5\% $(\mathbf{m l})$ & Aquadest $(\mathbf{m l})$ & Volume Akhir $(\mathbf{m l})$ & Pengenceran \\
\hline 1 & 6,5 & 7,5 & $1: 150$ \\
\hline 1 & 9 & 10 & $1: 200$ \\
\hline 1 & 11,5 & 12,5 & $1: 250$ \\
\hline 1 & 14 & 15 & $1: 300$ \\
\hline
\end{tabular}

Mengambil $10 \mathrm{ml}$ fenol lalu menambahkan aquadest hingga $100 \mathrm{ml}$, sehingga didapat produk dengan konsentrasi $10 \%$. Setelah itu membuat seri pengenceran dengan perbandingan berikut :

Tabel 2. Faktor Pengenceran Fenol

\begin{tabular}{cccc}
\hline Fenol 10\% $(\mathbf{m l})$ & Aquadest $(\mathbf{m l})$ & Volume Akhir $(\mathbf{m l})$ & Pengenceran \\
\hline 2 & 5 & 7 & $1: 70$ \\
\hline 2 & 6 & 8 & $1: 80$ \\
\hline 2 & 7 & 9 & $1: 90$ \\
\hline 2 & 8 & 10 & $1: 100$ \\
\hline
\end{tabular}

\subsection{Prosedur Analisa Koefisien Fenol}

Pengenceran dilakukan pada tiap produk dengan seri pengenceran 1:150, 1:200, 1:250 dan 1:300 dimana masing-masing sebanyak $0,5 \mathrm{ml}$ suspensi bakteri uji dimasukkan ke dalam tabung yang berisi $5 \mathrm{ml}$ medium NB lalu didiamkan selama 5 menit, Sebelum suspensi pertama diinkubasi, pada tabung reaksi yang lain suspensi tersebut diinokulasi $0,5 \mathrm{ml}$ suspensi bakteri ujidimasukkan ke dalam tabung yang berisi $5 \mathrm{ml}$ medium NB lalu didiamkan selama 5 menit kedua, Pada tabung reaksi yang lain(tabung reaksi ketiga), suspensi tersebut diinokulasi $0,5 \mathrm{ml}$ suspensi bakteri uji dimasukkan ke dalam tabung yang berisi $5 \mathrm{ml}$ medium NB lalu didiamkan selama 5 menit ketiga, Keseluruhan suspensi tersebut diinkubasi pada suhu kamar selama 48 jam, Lalu mengamati kekeruhannya. Diperkirakan bahan produk memiliki daya antibakteri. Adanya pertumbuhan bakteri ditandai $(+)$ dengan medium menjadi keruh, dan tidak adanya pertumbuhan ditandai (-) dengan medium tetap bening. 


\section{HASIL DAN PEMBAHASAN}

\subsection{Hasil Penelitian}

Tabel 3. Perbandingan analisa pH dan koefisien fenol pembersih lantai minyak jelantah pada berbagai variabel proses.

\begin{tabular}{|c|c|c|c|c|}
\hline No & Temperatur Pemanasan & $\begin{array}{c}\text { Konsentrasi } \\
\mathrm{NaOH}\end{array}$ & pH & $\begin{array}{c}\text { Koefisien } \\
\text { Fenol }\end{array}$ \\
\hline \multirow{4}{*}{1} & \multirow{4}{*}{$70^{\circ} \mathrm{C}$} & $10 \%$ & 6 & 1,66 \\
\hline & & $20 \%$ & 7 & 2,22 \\
\hline & & $30 \%$ & 9 & 2,77 \\
\hline & & $40 \%$ & 10 & 2,77 \\
\hline \multirow{4}{*}{2} & \multirow{4}{*}{$80^{\circ} \mathrm{C}$} & $10 \%$ & 7 & 2,22 \\
\hline & & $20 \%$ & 8 & 2,22 \\
\hline & & $30 \%$ & 10 & 2,77 \\
\hline & & $40 \%$ & 11 & 3,33 \\
\hline \multirow{4}{*}{3} & \multirow{4}{*}{$90{ }^{\circ} \mathrm{C}$} & $10 \%$ & 7 & 2,22 \\
\hline & & $20 \%$ & 9 & 2,22 \\
\hline & & $30 \%$ & 10 & 2,77 \\
\hline & & $40 \%$ & 11 & 2,77 \\
\hline \multirow{4}{*}{4} & \multirow{4}{*}{$100{ }^{\circ} \mathrm{C}$} & $10 \%$ & 8 & 1,66 \\
\hline & & $20 \%$ & 9 & 2,77 \\
\hline & & $30 \%$ & 10 & 2,77 \\
\hline & & $40 \%$ & 11 & 3,33 \\
\hline
\end{tabular}

Tabel 4 Analisa warna dan kelarutan dalam air pada berbagai variabel.

\begin{tabular}{|c|c|c|c|c|}
\hline No & $\begin{array}{l}\text { Temperatur } \\
\text { Pemanasan }\end{array}$ & $\begin{array}{c}\text { Konsentrasi } \\
\mathrm{NaOH}\end{array}$ & Warna & $\begin{array}{l}\text { Stabilitas Emulsi } \\
\text { dalam Air Sadah }\end{array}$ \\
\hline \multirow{4}{*}{1} & \multirow{4}{*}{$70{ }^{\circ} \mathrm{C}$} & $10 \%$ & Kuning & Stabil \\
\hline & & $20 \%$ & Coklat & Stabil \\
\hline & & $30 \%$ & Coklat & Stabil \\
\hline & & $40 \%$ & Coklat & Stabil \\
\hline \multirow{4}{*}{2} & \multirow{4}{*}{$80^{\circ} \mathrm{C}$} & $10 \%$ & Kuning & Stabil \\
\hline & & $20 \%$ & Coklat & Stabil \\
\hline & & $30 \%$ & Coklat & Stabil \\
\hline & & $40 \%$ & Coklat & Stabil \\
\hline \multirow{4}{*}{3} & \multirow{4}{*}{$90{ }^{\circ} \mathrm{C}$} & $10 \%$ & Coklat & Stabil \\
\hline & & $20 \%$ & Coklat & Stabil \\
\hline & & $30 \%$ & Coklat & Stabil \\
\hline & & $40 \%$ & Coklat & Stabil \\
\hline \multirow{4}{*}{4} & \multirow{4}{*}{$100^{\circ} \mathrm{C}$} & $10 \%$ & Coklat & Stabil \\
\hline & & $20 \%$ & Coklat & Stabil \\
\hline & & $30 \%$ & Coklat & Stabil \\
\hline & & $40 \%$ & Coklat & Stabil \\
\hline
\end{tabular}




\subsection{Pembahasan}

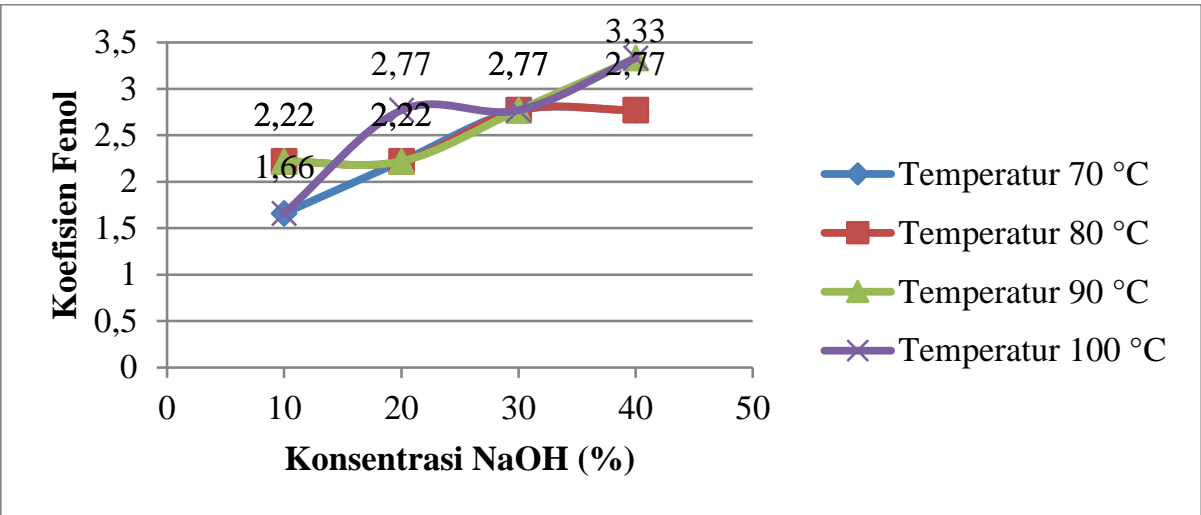

\section{Gambar 1. Grafik Hubungan Antara Konsentrasi NaOH dan Koefisien Fenol Terhadap Temperatur}

Berdasarkan gambar grafik diatas hubungan antara konsentrasi $\mathrm{NaOH}$ dan koefisien fenol terhadap temperatur, dapat diliat pada grafik berwarna hijau dan ungu dimana semakin tinggi konsentrasi $\mathrm{NaOH}$ dan temperatur maka koefisien fenol yang dihasilkan akan semakin tinggi. Pada pemasakan dengan temperatur yaitu $90{ }^{\circ} \mathrm{C}$ dan $100{ }^{\circ} \mathrm{C}$.

Hal ini sesuai dengan BSN (SNI-06-1842-1995) yang menyatakan bahwa nilai koefisien fenol pada karbol pembersih lantai minimal 2,50. Hal ini sesuai dengan teori yang menyatakan bahwa semakin tinggi $\mathrm{NaOH}$ maka semakin tinggi koefisien fenol didapat, namun pada analisa ini Jawetz (2005) mengatakan bahwa beberapa faktor dapat mempengaruhi kinerja produk antibakteri, antara lain seperti pada seri pengenceran produk tidak tepat, stabilitas komponen bahan aktif produk terganggu dan sebagainya. Sehingga diperlukan analisa lebih lanjut.

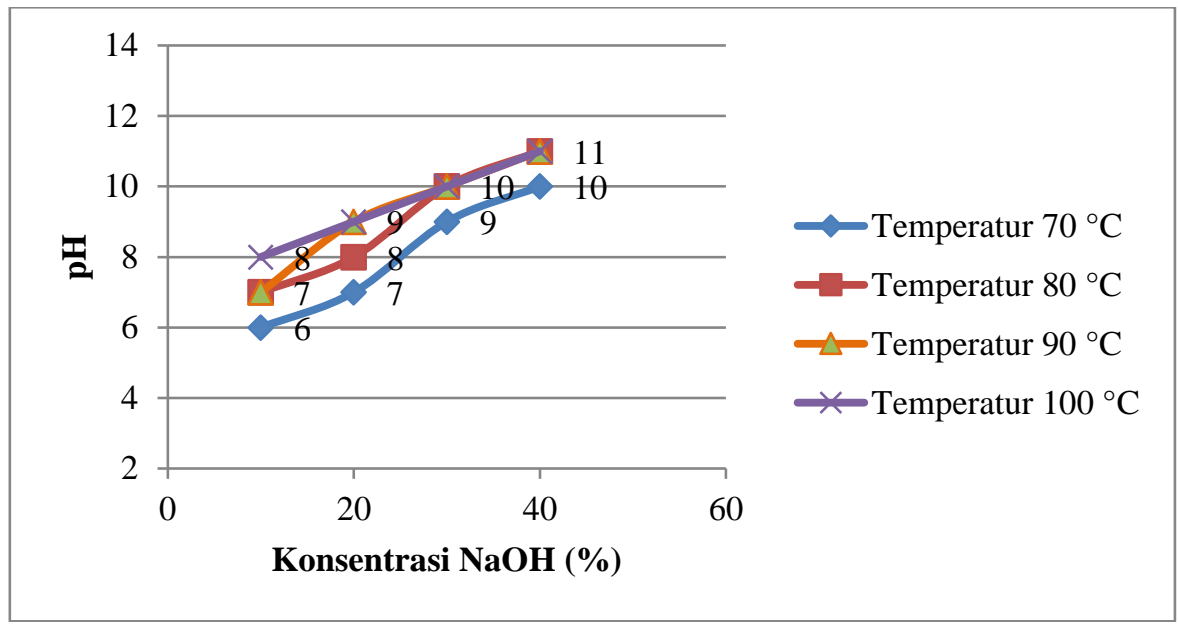

\section{Gambar 2. Grafik Hubungan Antara Konsentrasi NaOH dan pH Terhadap Temperatur}

Berdasarkan gambar grafik diatas hubungan antara konsentrasi $\mathrm{NaOH}$ dan koefisien fenol terhadap temperatur, dapat diliat pada grafik berwarna kuning dan ungu dimana semakin tinggi konsentrasi $\mathrm{NaOH}$ dan temperatur maka $\mathrm{pH}$ yang dihasilkan akan semakin tinggi. Pada pemasakan dengan temperatur $90{ }^{\circ} \mathrm{C}$ menghasilkan nilai $\mathrm{pH}$ yaitu 7,9 , 10, dan 11 .Pada pemasakan dengan temperatur $100{ }^{\circ} \mathrm{C}$ menghasilkan nilai pH yaitu 8, 9,10, dan 11 .

Hal ini sesuai dengan BSN (SNI-06-1842-1995) yang menyatakan bahwa nilai pH pada karbol pembersih lantai minimal 6-11. 


\subsection{Karakterisik Karbol dari Minyak Jelantah Dibandingkan dengan Karbol dari Minyak Pinus}

1. Bau

Hasil dimana karakteristik bau dari karbol minyak jelantah memiliki bau menyengat dan sedikit dari bau naftalena, dimana bau ini disebabkan adanya pengaruh penambahan naftalena menyebabkan hasil dari karbol minyak jelantah memiliki bau menyengat dan sedikit berbau naftalena.Sehingga, bau ini dapat dijadikan indikasi berhasilnya produk karbol dari minyak jelantah sebab karbol dari minyak pinus juga memiliki bau yang sama.

\section{Warna}

Karakteristik warna juga merupakan salah satu faktor yang dapat mempengaruhi proses terbentuknya karbol dari minyak jelantah. Berdasarkan hasil dari analisa dapat diketahui bahwa warna karbol dari minyak jelantah yang menggunakan metode pemanasan adalah coklat.Berbeda warna dari karbol dari minyak pinus yang identik memiliki warna kuning, warna pada karbol minyak jelantah memiliki warna coklat akibat dari pemanasan terlebih dahulu dan penambahan minyak jelantah.

\section{Stabilitas Emulsi dalam Air Sadah}

Hasil analisa menunjukkan bahwa karbol dari minyak jelantah hasil penelitianmembentuk emulsi yang stabil di dalam air sadah, tidak sama dengan karbol minyak pinus yang digunakan sebagai pembanding.

\section{SIMPULAN}

Karbol yang paling optimum diperoleh pada temperatur $90{ }^{\circ} \mathrm{C}$ dengan nilai koefisien fenol 2,22, 2,22, 2,77, dan 3,33 serta nilai $\mathrm{pH} 7,9,10$ dan 11. Pada temperatur $100^{\circ} \mathrm{C}$ dengan nilai koefisien fenol 1,66, 2,77, 2,77, dan 3,33 serta nilai pH 8, 9, 10, dan 11. Hal ini sesuai dengan BSN (SNI-06-1842-1995) yang menyatakan bahwa nilai koefisien fenol minimal 2,50 dan nilai pH minimal 6-11.

\section{DAFTAR PUSTAKA}

Depkes RI, 1996 "Pedoman Teknis Pengolahan Limbah Klinis Dan Desinfeksi \& Sterilisasi Di Rumah Sakit", Ditjen PPM dan PPL, Jakarta.

Fandi Akhmad, 2017 "Formulasi Cairan Pembersih Lantai dari Najis Mughalladzah dengan Variasi Konsentrasi Kaolin-Bentonit dan Variasi Konsentrasi Natrium Metasilikat”, UIN Syarif Hidayatullah, Jakarta.

Ketaren S, 2005 “Pengantar Teknologi Minyak dan Lemak Pangan”, Universitas Indonesia, Jakarta. Latiful Qolby, Achmad, Meliana Ningrum, Mirna Tiarani Putri, Muhammad Didik Setyawan, Nusaibah Askariyah, 2017 “Pemanfaatan Minyak Jelantah Untuk Pembuatan Karbol”, Jurnal Program Studi Kimia Fakultas Sains dan teknologi Universitas Hidayatullah, Jakarta.

Mahreni, 2010" Peluang dan Tantangan Komersialisasi Biodisel Review" Jurnal Jurusan Teknik Kimia Universitas Pembangunan Nasional "Veteran" Yogyakarta.

Sumarlin La Ode, Lela Mukmillah, Ratna Istianah, 2008 " Analisis Mutu Minyak Jelantah Hasil Peremajaan Menggunakan Tanah Diatomit Alami dan Terkalsinasi” Program Studi Kimia FTS UIN syarif Hidayatullah, Jakarta.

Tamrin, 2013 “ Gasifikasi Minyak Jelantah Pada Kompor Bertekanan” Jurnal Teknik Pertanian Lampung, Universitas Lampung.

Geminastiti, 2012. "Sifat Fisik dan Kimia Minyak Jelantah". http://nunukgeminastiti.blogspot.co.id/2012/03/biodiesel.html. 